(C) 2021, The Authors. Published by Elsevier Inc. and Fass Inc. on behalf of the American Dairy Science Association ${ }^{\circledR}$. This is an open access article under the CC BY-NC-ND license (http://creativecommons.org/licenses/by-nc-nd/4.0/).

\title{
Mycoplasma species isolated from bovine milk collected from US dairy herds between 2016 and 2019
}

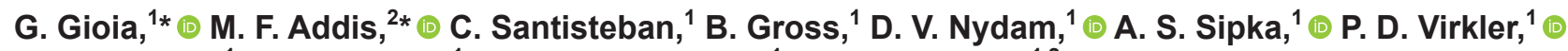

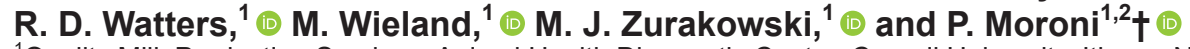 \\ ${ }^{1}$ Quality Milk Production Services, Animal Health Diagnostic Center, Cornell University, Ithaca, NY 14853 \\ ${ }^{2}$ Università degli Studi di Milano, Dipartimento di Medicina Veterinaria, Via dell'Università, 6, 26900 Lodi, LO, Italy
}

\begin{abstract}
Determining the species of mycoplasma isolated from culture-positive milk samples is important for understanding the clinical significance of their detection. Between August 2016 and December 2019, 214,518 milk samples from 2,757 dairy herds were submitted to Quality Milk Production Services (QMPS) at Cornell University for mycoplasma culture. From these samples, 3,728 collected from 204 herds were culture positive. Based on the request of herd managers, owners, or veterinarians, 889 isolates from 98 herds were subjected to molecular identification by PCR and amplicon sequencing. The largest proportion of the identified isolates were from New York State $(78.1 \%)$, while the others came from the eastern United States (17.8\%), Texas (2.0\%), and New Mexico (2.1\%). As expected, Mycoplasma spp. were the most common (855 isolates, 96.2\%) and Acholeplasma spp. accounted for the remainder (34 isolates, 3.8\%). Mycoplasma bovis was the most prevalent Mycoplasma species (75.1\%), followed by $M$. bovigenitalium (6.5\%), M. canadense (5.9\%), $M$. alkalescens (5\%), M. arginini (1.7\%), M. californicum $(0.1 \%)$, and $M$. primatum $(0.1 \%)$. A portion of the isolates were confirmed as Mycoplasma spp. other than $M$. bovis but were not identified at the species level (16 isolates, 1.8\%) because further information was not requested by the manager, owner, or veterinarian. Mycoplasma bovis was the only species identified in 59 of the 98 herds. However, more than 1 Mycoplasma sp. was identified in 29 herds, suggesting that herd infection with 2 or more mycoplasmas is not uncommon. Moreover, a Mycoplasma sp. other than M. bovis was the only species identified in 8 herds. From the subset of 889 mycoplasma culture-positive isolates from 98 herds,
\end{abstract}

Received June 27, 2020.

Accepted November 30, 2020.

*These authors contributed equally to this work.

†Corresponding author: pm389@cornell.edu we determined that over a third of the herds had either more than 1 Mycoplasma sp. or a Mycoplasma sp. other than $M$. bovis detected in their milk samples. In conclusion, we observed that $M$. bovis is the most common pathogenic Mycoplasma species found in mastitic milk, but other Mycoplasma species are not uncommon. Our results suggest that it is critical to test milk samples for mycoplasmas using diagnostic tests able to identify both the genus and the species.

Key words: Mycoplasma bovis, Mycoplasma spp., Acholeplasma spp., mastitis, molecular identification

\section{INTRODUCTION}

Mastitis leads to substantial economic losses in the dairy industry, and the timely identification of etiological agents can significantly contribute to controlling the disease (Blosser, 1979). This identification is even more relevant for contagious pathogens such as Mycoplasma spp., which represent an important target for herd survey screening in the United States and other parts of the world (Fox et al., 2005; Barkema et al., 2009; Nicholas et al., 2016). Mycoplasma spp. are considered among the most important pathogens in cattle systems of industrialized and developing countries (Nicholas, 2011), causing clinical, subclinical, and chronic IMI that can persist through the current lactation and into subsequent lactations (Fox, 2012; Nicholas et al., 2016; Parker et al., 2018). Although the prevalence is not as high as for some other pathogens, Mycoplasma IMI can result in severe udder disease (Fox et al., 2003). Mycoplasma IMI are usually highly contagious; they can affect more than one quarter, cause significant decreases in milk yield, and do not respond to antimicrobial treatment (Jasper, 1981; Britten, 2003) or therapy (Bushnell, 1984). Culling remains the most common recommendation for controlling Mycoplasma infections (Britten, 2003). In countries with large dairy herds, Mycoplasma IMIs are a significant concern, and more than $21 \%$ of large dairies with over 500 cows may be affected in the United States (APHIS, 2003). 
Historically, the most relevant Mycoplasma species reported to cause IMI in cattle is $M$. bovis, but other species have also been isolated from cow milk (Boonyayatra et al., 2011; Fox, 2012), and mixed $M y$ coplasma infections may occur in a herd and be associated with disease (González and Wilson, 2003; Pinho et al., 2013). Therefore, knowledge of the circulating Mycoplasma species, their co-occurrence with M. bovis, and their involvement in mastitis cases could result in the use of appropriate molecular diagnostic tests for their detection, enabling timely management decisions to control outbreaks and prevent new cases.

According to the National Mastitis Council (NMC) guidelines, the gold standard method to detect mycoplasmas in milk samples is based on bacteriological culture on selective solid media and the growth of colonies with the typical "fried-egg" appearance in positive samples (NMC 2017; Parker et al., 2018). Standard bacteriological culture does not differentiate Mycoplasma spp. from Acholeplasma spp. due to their similar colony morphology. Knowing the species of Mycoplas$m a$ isolated from the milk is useful information, but the distinction between bacterial genera is also critical because it is not entirely clear if Acholeplasma spp. can act as a primary pathogen. Deciphering Mycoplasma spp. from Acholeplasma spp. is important because historically Acholeplasma spp. have often been considered as nonpathogenic saprophytic milk contaminants originating from the soil, compost, and wastewater (Jasper, 1982). An alternative culture-based test for discriminating Mycoplasma spp. from Acholeplasma spp. relies on antimicrobial discs with digitonin or nisin producing inhibition zones with different sizes for the 2 genera (Boonyayatra et al., 2012), but the results are often difficult to interpret (Parker et al., 2018). To overcome these limitations, the Quality Milk Production Services (QMPS) laboratories at the Animal Health Diagnostic Center, Cornell University (Ithaca, NY) have developed a molecular speciation test that is offered after the detection of suspected Mycoplasma colonies from a milk sample (Gioia et al., 2016).

This study presents the results obtained from milk samples submitted over a 40-mo period to QMPS for mycoplasma detection from dairy herds located in New York and in other eastern US states, Texas, and New Mexico. We determined the species of a subselection of mycoplasma culture-positive isolates and describe the geographical distribution of the identified species isolated by culture according to the location of the dairy herds from which the milk samples were obtained. From the outcome of our data, we evaluated the occurrence and the distribution patterns of the different $M y$ coplasma species, and we investigated the occurrence of mixed infections within dairy herds.

\section{MATERIALS AND METHODS}

\section{Milk Samples}

Milk samples $(214,518)$ from 2,757 US dairy herds were received for mycoplasma testing at QMPS laboratories between August 2016 and December 2019. Milk was collected or received from individual quarters (clinical quarter milk samples), combined from multiple quarters of a cow into one sample tube (composite milk samples), or from bulk tanks. Composite samples were tested as a herd survey or for the screening of freshly calved cows, cows with high SCC, or cows in the hospital pen. Pooled samples were quarter or composite samples from 3 to 5 cows combined.

\section{Bacteriology}

Milk samples were subjected to standard mycoplasma culture methods described in the NMC guidelines (NMC, 2017) in the context of the diagnostic routine at QMPS. Modified Hayflick medium (Northeast Laboratory) was used for mycoplasma isolation. Milk samples were mixed by inversion and a sterile cotton swab applicator was used to spread milk samples onto one-half of a standard Petri dish. After $7 \mathrm{~d}$ of incubation at $37^{\circ} \mathrm{C}$ in an atmosphere of $>95 \%$ humidity and $5 \%$ carbon dioxide, all plates were examined under an illuminated stage stereomicroscope (Olympus SZH-ILLB) for visualizing colonies with morphology consistent with Mycoplasma spp.

\section{Molecular Identification}

Based on voluntary requests by herd owners, managers, or veterinarians, a subset of the mycoplasmapositive samples were subjected to further molecular testing. This testing used a multitarget PCR assay that enabled identifying $M$. bovis at the species level and discriminating Mycoplasma from Acholeplasma at the genus level (Gioia et al., 2016). Molecular tests were performed directly on colonies grown on the mycoplasma agar plates that exhibited suspicious or typical friedegg morphology. Agar plates submitted for molecular testing were processed immediately or after a maximum storage of $15 \mathrm{~d}$ at $4^{\circ} \mathrm{C}$. In the diagnostic routine, the assay can confirm or reject a presumptive positive mycoplasma culture result for which a single colony or atypical growth prevents a conclusive identification as Mycoplasma spp. Isolates confirmed as Mycoplasma spp. but not identified as $M$. bovis can be identified at the species level through an optional further step that includes Sanger sequencing of the PCR amplicons and subsequent sequence analysis. The same process is 
Table 1. Distribution of the 3,728 samples testing positive for Mycoplasma by bacterial culture from 2016 to 2019 at the Quality Milk Production Services laboratories (Ithaca, NY)

\begin{tabular}{lcccc}
\hline & \multicolumn{3}{c}{ Sample type } \\
\cline { 2 - 4 } Geographical origin & Tank $^{1}$ & Pooled $^{2}$ & Composite $^{3}$ & Quarter $^{4}$ \\
\hline New York State & 458 & 740 & 1,324 & 480 \\
Non-New York State & 164 & 142 & 314 & 106 \\
Total & 622 & 882 & 1,638 & 586 \\
\hline${ }^{1}$ Milk collected from the bulk tank. & & \\
${ }^{2}$ Combined milk from 3 to 5 cows. \\
${ }^{3}$ Combined milk from quarters of the same cow. \\
${ }^{4}$ Quarter milk from 1 cow.
\end{tabular}

also done in the case of Acholeplasma-positive samples in the PCR. All sequence analyses were offered as an optional step performed only if the client's consent was received. A small portion of veterinarians or farmers declined to pursue the availability of further speciation when samples resulted in Mycoplasma species other than M. bovis. For those clients, a Mycoplasma confirmation test with only the identification or exclusion of $M$. bovis presence was considered enough to make management decisions. Most veterinarians or farmers who sent samples that were identified as containing Acholeplasma spp. declined the option to proceed for further speciation because they perceived no additional value in knowing which species of Acholeplasma was present.

\section{Data Analysis}

The data were extracted from the Veterinary Hospital \& Laboratory Management System (VetView), which is used to enter all client and testing information submitted to the Animal Health Diagnostic Center. Using Tableau (Tableau Software), an intelligence software used for data analysis and data visualization, we ran queries to obtain relevant information. The data were exported using .csv format and imported into Microsoft Excel (2016 version, Microsoft Corp.) for further analyses. The data related to the speciation results were taken from Excel worksheet records maintained in the QMPS Molecular Laboratory. All the data used for the present study were summarized and descriptive statistics are presented.

\section{RESULTS}

\section{Herd Locations, Milk Sample Types, and Proportion of Samples Positive for Mycoplasma Culture}

Out of 214,518 milk samples cultured for the presence of Mycoplasma, 199,885 (93.2\%) were from New York State and 14,633 (6.8\%) were from other states (eastern states, Texas, and New Mexico). The distribution based on sample types included 12,231 bulk tank $(5.7 \%), 84,098$ pooled $(39.2 \%), 88,407$ composite $(41.2 \%)$, and 29,782 quarter $(13.9 \%)$. Of all the milk samples tested, 3,728 (1.7\%) grew Mycoplasma colonies on culture. The state distribution (NY and non-NY) of culture-positive milk samples according to the sample type is summarized in Table 1.

\section{Mycoplasma and Acholeplasma Species Identified in Culture-Positive Milk Samples}

Of the 3,728 Mycoplasma culture-positive samples, $889(23.8 \%)$ were subjected to molecular identification of the isolate; 694 (78.1\%) were from New York and $195(22.8 \%)$ were from other states. Figure 1 illustrates their geographical distribution. Details on samples and herds are provided in Table 2.

At the genus level, $96.2 \%$ of all 889 speciated isolates were Mycoplasma spp., while $3.8 \%$ were Acholeplasma spp. Mycoplasma bovis was the most frequently identified species (75.1\%), followed by Mycoplasma bovigenitalium (6.5\%) and Mycoplasma canadense (5.8\%). All identified species are presented in Table 3.

The 889 identified isolates originated from the following sample types: 190 bulk tank, 196 pooled, 354 composite, and 149 quarter milk. The distribution of the Mycoplasma spp. varied in the different sample types. Figure 2 illustrates the percentage of Mycoplasma and Acholeplasma species according to the sample type (bulk tank, pooled, composite, and quarter).

Mycoplasma bovis was the species identified most frequently in all sample types, accounting for $82.2 \%$, $79.7 \%$, and $65.8 \%$ of isolates identified from composite, bulk tank, and quarter samples, respectively. Among Mycoplasma spp. other than M. bovis, M. bovigenitalium was identified most often in quarter samples $(13.4 \%), M$. canadense in pooled samples (14.3\%), and Mycoplasma alkalescens and Mycoplasma arginini in bulk tank samples (10.0 and 3.7\%, respectively). $M y$ coplasma californicum was identified in only 1 pooled 


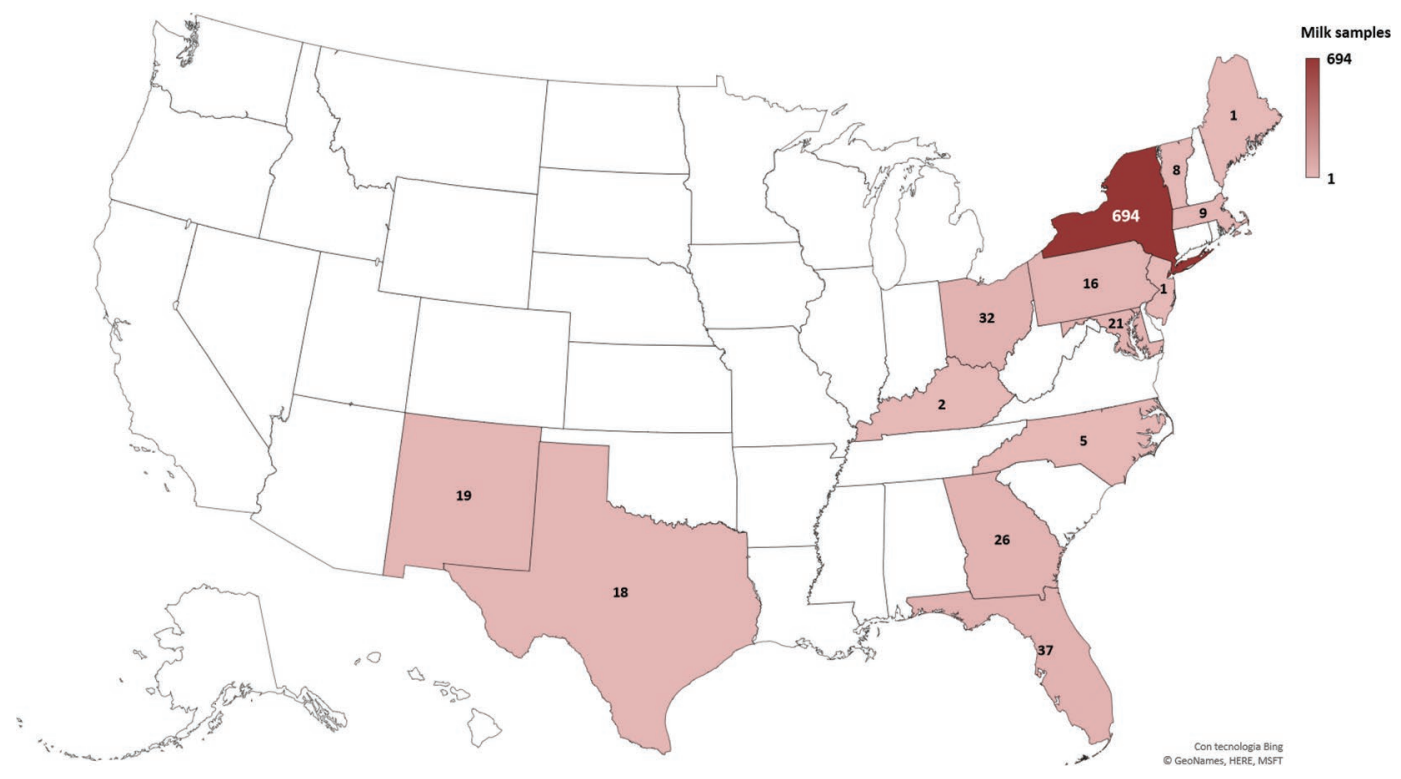

Figure 1. Geographical distribution of 889 milk samples submitted from 2016 to 2019 to Quality Milk Production Services laboratories (Ithaca, NY) producing the Mycoplasma and Acholeplasma isolates that were subjected to molecular identification.

sample, and Mycoplasma primatum in only 1 quarter sample. Some isolates that were not M. bovis (Mycoplasma spp.) were not identified further because the request was not made. These isolates originated most frequently from quarter milk samples (4.0\%). Finally, Acholeplasma spp. were isolated most often in composite samples $(6.2 \%)$.

\section{Isolation of Single or Multiple Mycoplasma and Acholeplasma Species in the Tested Herds}

The presence of single or multiple species of $\mathrm{Myco-}$ plasma and of Acholeplasma in the tested herds is re-

Table 2. Geographical distribution of 889 Mycoplasma or Acholeplasma isolates from milk samples submitted for bacterial culture from 2016 to 2019 to Quality Milk Production Services laboratories (Ithaca, NY), and of the 98 herds from which they originated

\begin{tabular}{lcc}
\hline State & $\begin{array}{c}\text { No. of milk } \\
\text { samples (\%) }\end{array}$ & $\begin{array}{c}\text { No. of } \\
\text { herds }(\%)\end{array}$ \\
\hline New York & $694(78.1)$ & $66(67.4)$ \\
Florida & $37(4.1)$ & $4(4.1)$ \\
Georgia & $26(3.1)$ & $1(1.0)$ \\
Kentucky & $2(0.2)$ & $1(1.0)$ \\
Massachusetts & $9(1.0)$ & $2(2.0)$ \\
Maryland & $21(2.4)$ & $4(4.1)$ \\
Maine & $1(0.1)$ & $1(1.0)$ \\
North Carolina & $5(0.6)$ & $1(1.0)$ \\
New Jersey & $1(0.1)$ & $1(1.0)$ \\
New Mexico & $19(2.1)$ & $2(2.0)$ \\
Ohio & $32(3.5)$ & $5(5.2)$ \\
Pennsylvania & $16(1.8)$ & $4(4.1)$ \\
Texas & $18(2.0)$ & $2(2.0)$ \\
Vermont & $8(0.9)$ & $4(4.1)$ \\
\hline
\end{tabular}

ported in Table 4 . In most herds, $M$. bovis was the only species isolated from milk (60.2\%). A smaller percentage of herds had positive results due to Mycoplasma spp. other than $M$. bovis (8.2\%), and 2 herds showed only Acholeplasma spp. (2.0\%). In several herds, however, we detected the presence of $M$. bovis together with other Mycoplasma spp. (20.4\%), sometimes also together with Acholeplasma spp. (9.2\%). The species found most often in these co-infections with $M$. bovis were $M$. bovigenitalium, M. alkalescens, $M$. canadense, and $M$. arginini, respectively. Most of the herds (65\%) with more than 1 species detected showed the presence of only 1 other Mycoplasma sp. in addition to $M$. bovis, while the remaining herds had 2 or more other Mycoplasma species detected. Mycoplasma arginini was detected only in herds with a large variety of other species found.

Table 3. Molecular identification of 889 Mycoplasma or Acholeplasma isolates from milk samples submitted for bacterial culture from 2016 to 2019 to Quality Milk Production Services laboratories (Ithaca, NY)

\begin{tabular}{lccc}
\hline Species & $\begin{array}{c}\text { New York } \\
\text { State }\end{array}$ & $\begin{array}{c}\text { Non-New } \\
\text { York State }\end{array}$ & $\begin{array}{c}\text { Total, } \\
\text { no. }(\%)\end{array}$ \\
\hline M. bovis & 511 & 157 & $668(75.1)$ \\
M. bovigenitalium & 53 & 5 & $58(6.5)$ \\
M. . anadense & 51 & 1 & $52(5.9)$ \\
M. alkalescens & 24 & 20 & $44(5.0)$ \\
M. arginini & 12 & 3 & $15(1.7)$ \\
M. .alifornicum & 1 & 0 & $1(0.1)$ \\
M. primatum & 1 & 0 & $1(0.1)$ \\
Mycoplasma spp. ${ }^{1}$ & 8 & 8 & $16(1.8)$ \\
${\text { Acholeplasma } \text { spp. }^{1}}$ & 33 & 1 & $34(3.8)$ \\
\hline
\end{tabular}

${ }^{1}$ The species was not identified with the PCR method. 
Table 4. Occurrence of Mycoplasma bovis, other Mycoplasma spp., and Acholeplasma spp., in 98 herds sending their samples from 2016 to 2019 to Quality Milk Production Services laboratories (Ithaca, NY) for which molecular identification of Mycoplasma or Acholeplasma isolates was performed

\begin{tabular}{lc}
\hline Bacterial species present at the farm & $\begin{array}{c}\text { No. of } \\
\text { herds }(\%)\end{array}$ \\
\hline M. bovis only & $59(60.2)$ \\
M. bovis and other Mycoplasma spp. & $20(20.4)$ \\
M. bovis, other Mycoplasma spp., and & $9(9.2)$ \\
Acholeplasma spp. & $8(8.2)$ \\
Mycoplasma spp. different than $M$. bovis only & $2(2.0)$ \\
\hline
\end{tabular}

\section{DISCUSSION}

We present the results from routine mycoplasma cultures of bulk tank, pooled, composite, and quarter milk samples submitted to QMPS laboratories between 2016 and 2019. For a portion of the isolates testing positive for Mycoplasma in culture, further molecular tests were performed to identify the species. This study demonstrated the presence of $M$. bovis across several states. Additionally, other Mycoplasma species with pathogenic potential were detected in notable numbers from several herds. This information is important for herd owners, managers, and veterinarians to know when selecting appropriate species-specific PCR tests for diagnosis of mycoplasmal mastitis. Diagnoses could be missed if only a $M$. bovis PCR is carried out in herds in which mastitis is caused by other Mycoplasma species. Co-infections with $M$. bovis were also detected in some herds. This study also highlighted the presence of Acholeplasma spp., which could be mistaken for Myco- plasma spp. if only standard bacteriological cultures are used for diagnostic testing.

The detection of mycoplasmas in the different sample types has various interpretations: (1) the detection in bulk tank milk shows that Mycoplasma is present within a herd, (2) the detection within composite samples without clinical signs of mastitis is indicative of subclinical infections, and (3) the detection within clinical quarter milk samples suggests that Mycoplasma is possibly causing the mastitis. The value of knowing the genus and species of Mycoplasma is different for each sample type and is highly dependent on the individual farm situation.

\section{Bulk Tank Milk Samples}

Testing bulk tank milk samples is a good way to survey herds for infectious agents capable of causing mastitis, including Mycoplasma species. In our survey, $M$. bovis was the most common mycoplasma species detected for 190 mycoplasma culture-positive bulk tank milk samples from 98 herds across 14 states. Mycoplasma alkalescens, M. arginini, M. bovigenitalium, and $M$. canadense were also detected, in order of abundance. Of these, $M$. bovigenitalium and $M$. canadense have been reported to cause mastitis (Jackson and Boughton, 1991; Mackie et al., 2000; Fox, 2012). Mycoplasma alkalescens and M. arginini have also been previously isolated from bulk milk, but less evidence exists to suggest they cause mastitis (Kokotovic et al., 2007; Justice-Allen et al., 2011). In the present study, M. arginini was isolated most frequently from bulk tank samples from farms where we also detected other Mycoplasma

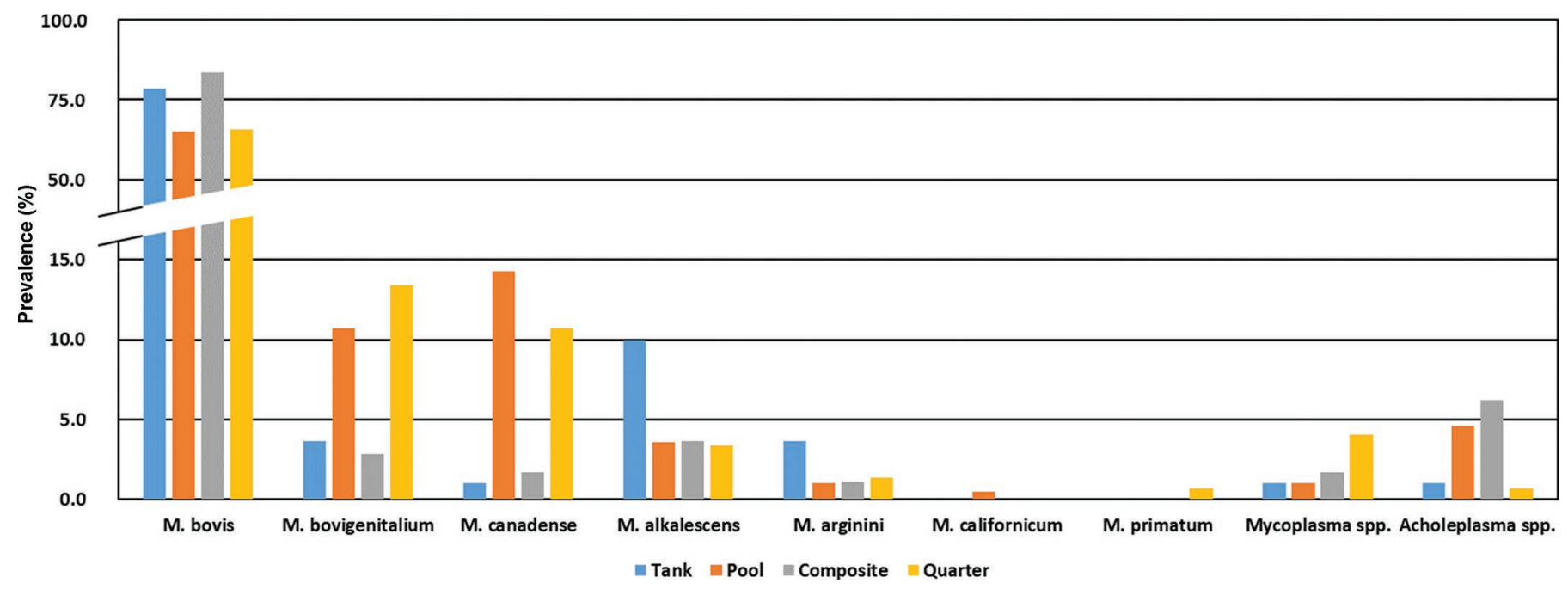

Figure 2. Percentages of Mycoplasma bovis, other Mycoplasma spp., and Acholeplasma spp., in bulk tank, pool, composite, and quarter milk. The class Mycoplasma spp. includes the isolates that were not $M$. bovis but were not processed for further speciation. The y-axis is broken for a better visualization of lower-abundance species. 
species. We found no reports of mastitis caused by $M$. arginini, although this species is frequently detected in bulk milk originating from herds affected by mastitis of different etiologies (Fox et al., 2005; Higuchi et al., 2011; Justice-Allen et al., 2011).

The observation of $M$. bovis as the main species identified in bulk tank milk is consistent with the data presented by Britten et al. (2020) at the 59th National Mastitis Council Annual Meeting. Mycoplasma bovigenitalium and $M$. alkalescens were the second and third most commonly identified species, respectively. However, M. californicum was more common than $M$. canadense.

In our experience, the vast majority of herd managers, owners, or veterinarians decide to pursue the genus and species identification for bulk tank samples once they are given the option. According to guidelines of QMPS's veterinarians, if a bulk tank sample is positive for $M$. bovis, then action is needed to determine which individual cows are infected, so that they can be removed. If a bulk tank sample comes back as positive for Acholeplasma, then the advice is to resample the bulk tank after a period of time. If a bulk tank sample is positive for Mycoplasma species other than M. bovis, including $M$. alkalescens, M. bovigenitalium, M. californicum, or M. canadense (González and Wilson, 2003; Mackie at al., 1982, 1986), then the herd manager, owners, or veterinarian may decide if it is worth the effort and expense to find the individual cows. If it is any of the Mycoplasma spp. other than M. bovis, then resampling the bulk tank after a period of time would be advised.

\section{Composite Milk Samples}

Composite milk samples submitted to our laboratories were from herds surveying groups of cows that had freshly calved, had high SCC, or were contained within the hospital pen. We observed a higher than expected number of Mycoplasma-infected cows based on composite samples (1.9\%). Most of the composite samples found to be positive were collected from cows without signs of clinical mastitis in the context of herd screening programs or from cows belonging to herds in which clinical Mycoplasma cases had been diagnosed. These subclinical infections could be self-limiting or the species identified may vary in pathogenicity (González and Wilson, 2003; Nicholas et al., 2016). Intermittent shedding is an important feature of subclinical $M y$ coplasma infections (Biddle et al., 2003; Caswell and Archambault, 2007; Hazelton et al., 2018) and therefore needs to be considered a limiting factor if attempting to detect subclinical infections. Interestingly, Hazelton et al. (2020) do not advise testing whole herds for the detection of $M$. bovis subclinical infections after all clinical mastitis cases have been culled following an outbreak. To overcome this issue, it is important that farms are periodically screened (Rosenbusch, 2003).

In our mycoplasma culture-positive composite samples, most contained $M$. bovis $(82.2 \%)$, followed by Acholeplasma spp. (6.2\%), M. alkalescens (3.7\%), or M. bovigenitalium (2.8\%). For composite samples, the value of pursuing genus or species testing was highly dependent on the individual herd situation. Very little information on this sample type for Mycoplasma spp. other than M. bovis or for Acholeplasma has been published in the literature, making a definitive decision more difficult.

For some herd situations in which the tolerance for Mycoplasma is very low, the veterinarian or manager stated that pursuing genus or species identification has no value because the cow will be culled anyway to reduce the risk to the rest of the herd. In other herd situations, however, the veterinarian or manager elected to pursue genus or species identification to make sure that cows were not inappropriately culled for being mycoplasma culture positive with Acholeplasma or with a Mycoplasma sp. other than $M$. bovis that has questionable mammary gland pathogenicity. When these latter situations are found for composite samples, a review of the sample collection procedure is initiated and the individual cows are segregated, monitored by SCC, and retested.

\section{Quarter Milk Samples}

Quarter milk samples submitted to our laboratories were from clinical mastitis cases. In quarter samples, $M$. bovis $(65.8 \%)$ was followed by $M$. bovigenitalium (13.4\%), M. canadense (10.7\%), M. alkalescens (3.4\%), and M. arginini (1.3\%); other Mycoplasma spp. (4.7\%) and Acholeplasma spp. (0.7\%) were also found. For quarter samples that were assumed to be from cows with clinical mastitis, some herd managers, owners, and veterinarians stated that knowing the species of Mycoplasma had no value because the cow would be a cull candidate in any case for the benefit of the herd (Pfützner and Sachse, 1996). Others perceived value in case of sample contamination at the time of collection and wanted to differentiate Mycoplasma from Acholeplasma (Jasper et al., 1979, 1981; Bushnell, 1984) or to identify Mycoplasma spp., such as $M$. arginini, that have not been shown to cause mastitis (Stipkovits et al., 2013). Previous studies have suggested that $M$. arginini does not cause mastitis but significantly predisposes the animal to infection with Streptococcus dysgalactiae leading to severe mastitis (Stipkovits et al., 2013). Mycoplasma arginini is frequently isolated from various animal spe- 
cies with different pathological conditions, such as from cattle with respiratory disease (Thomas et al., 2002; Ayling et al., 2004). It has been demonstrated that $M$. arginini can persist for a long time under different environmental conditions (Nagatomo et al., 2001). Only a mild decrease in milk production and a slight increase in SCC were noticed after challenging cows with $M$. arginini into the udder (Stipkovits et al., 2013).

When Acholeplasma or Mycoplasma spp. other than $M$. bovis with questionable pathogenicity are found, the veterinarian and managers have typically advised segregating the cow, so that she is not a risk to the herd, and monitoring her over time to determine if she clears the infection and returns to low SCC and mycoplasma culture-negative status.

Concerning Mycoplasma species other than M. bovis, we found $M$. bovigenitalium and $M$. canadense mostly in quarter and pooled samples. Also, we often identified $M$. bovigenitalium in farms showing the concurrent presence of multiple species. Their mammary gland pathogenicity and virulence factors are poorly known, and our prominent identification of these non-M. bovis species in quarter milk, typically collected from clinical mastitis cases, suggests their possible role in mammary gland health and deserves further investigation.

Transmission of Mycoplasma can occur internally, and a single clone of bovine Mycoplasma could affect and cause disease in multiple body sites over several months in cattle of all ages (Djordjevic et al., 2001; Punyapornwithaya et al., 2010). This is the case for $M$. bovigenitalium, which is frequently isolated from milk samples but is also reported to be associated with diseases of the reproductive tract (Catania at al., 2014; Hata et al., 2017; Parkinson, 2019).

In addition to the species typically found in cow milk, we isolated Mycoplasma primatum from a clinical mastitis quarter milk sample. This species has not been isolated from milk samples or the dairy environment previously, but it is commonly found in the oral and urogenital tracts of primates (DelGiudice et al., 1971).

Independent of sample type considerations, another interesting observation emerging from our study was the presence of co-infections by $M$. bovis and other Mycoplasma spp., sometimes also together with Acholeplasma spp., in the same herd. The species most commonly found in these coinfections were $M$. bovigenitalium, M. alkalescens, M. canadense, and M. arginini, respectively. Mycoplasma arginini was detected only in herds with a large variety of other species found. This finding also calls for more investigations to determine if other species have a direct influence on mammary gland health or if they have only a nonclinical or productionrelated effect. Also, other diagnostic approaches may be useful in these cases, such as evaluating the possible co-occurrence of other mastitis pathogens detectable by aerobic cultures.

Mycoplasma species identification using molecular methods may help to clarify the role played by different Mycoplasma spp. in udder health, and it also differentiates Mycoplasma from Acholeplasma. The consequences of Acholeplasma isolation from milk have not been investigated in detail, and it remains unknown whether these bacteria are present in milk as IMI agents or as simple contaminants (Quinn et al., 2013; Parker et al., 2018), resulting from incorrect sampling procedures or from transient presence in the udder. In this study, Acholeplasma was only identified in $3.8 \%$ of culture-positive samples and, of these, in only $0.7 \%$ of all quarter milk samples (most likely with clinical mastitis), demonstrating no significant association with mastitis. Bulk tank, pooled, and composite milk samples were more likely to be contaminated with Acholeplasma. With regard to the sampling practices, it is more difficult to collect composite samples than quarter samples. Composite samples have a higher chance of contamination because the vials are kept open for a long time and undergo repositioning under the cow udder. This could explain why a greater proportion of the composite samples were Acholeplasma positive.

In the future, implementing direct quantitative PCR in milk may significantly reduce time to results, but assay conditions will have to be carefully defined to avoid specificity issues, and cost-benefit considerations for the farmers will have to be made (Parker et al., 2018). Also, as mentioned above, most of the quantitative PCR assays available only target $M$. bovis, and the current study further confirms that other species are routinely isolated from milk. A PCR for $M$. bovis alone would not be suitable in $8.2 \%$ of the herds in which $M$. bovis was not the species cultured, and this fact will have to be accounted for when implementing PCR as the only testing method.

In conclusion, M. bovis was the most common mycoplasma species identified in the milk samples tested in our laboratories, but Mycoplasma spp. other than $M$. bovis as well as Acholeplasma spp. were routinely found. In addition, isolation of multiple species from the same herd was not uncommon. Therefore, determining the species of any mycoplasma culture-positive sample is important to inform the herd owner, manager, or veterinarian on the clinical significance of the isolate and guide possible PCR tests available to those herds for future mastitis cases due to Mycoplasma. In the future, a better knowledge of the distribution of non- $M$. bovis species and of their relationships with clinical signs in the herd will improve our understanding of the epide- 
miology and the relevance of other Mycoplasma species in milk production losses, enabling more meaningful testing and management decisions.

\section{ACKNOWLEDGMENTS}

This paper is dedicated to Frank "Google" Welcome for all the time we spent discussing Mycoplasma in the United States. Frank's wealth of insight provided us the opportunity to increase our knowledge of mastitis. We learned so many things from Frank, but the most important message we received was simply to love and have a great passion for the work we do. This research was supported by the Hatch grant funding the project "Mycoplasma in dairy farms: Evaluation of a novel enrichment real-time PCR for rapid management," 2018-2020 Moroni (principal investigator) project number NYC-2018-19-131. The authors have no conflicts of interest to report.

\section{REFERENCES}

APHIS. 2003. Mycoplasma in bulk tank milk in U.S. dairies. APHIS Info Sheet N395.053. APHIS, Fort Collins, CO.

Ayling, R. D., S. E. Bashiruddin, and R. A. Nicholas. 2004. Mycoplasma species and related organisms isolated from ruminants in Britain between 1990 and 2000. Vet. Rec. 155:413-416. https://doi .org/10.1136/vr.155.14.413.

Barkema, H. W., M. J. Green, A. J. Bradley, and R. N. Zadoks. 2009. The role of contagious disease in udder health. J. Dairy Sci. 92:4717-4729. https://doi.org/10.3168/jds.2009-2347.

Biddle, M. K., L. K. Fox, and D. D. Hancock. 2003. Patterns of mycoplasma shedding in the milk of dairy cows with intramammary mycoplasma infection. J. Am. Vet. Med. Assoc. 223:1163-1166. https://doi.org/10.2460/javma.2003.223.1163.

Blosser, T. H. 1979. Economic losses from and the national research program on mastitis in the United States. J. Dairy Sci. 62:119-127. https://doi.org/10.3168/jds.S0022-0302(79)83213-0.

Boonyayatra, S., L. K. Fox, T. E. Besser, A. Sawant, J. M. Gay, and Z. Raviv. 2011. Identification of Mycoplasma species using novel realtime PCR assay. Pages 120-124 in 3rd International Symposium on Mastitis and Milk Quality.

Boonyayatra, S., L. K. Fox, J. M. Gay, A. Sawant, and T. E. Besser. 2012. Discrimination between Mycoplasma and Acholeplasma species of bovine origin using digitonin disc diffusion assay, nisin disc diffusion assay, and conventional polymerase chain reaction. J. Vet. Diagn. Invest. 24:7-13. https://doi.org/10.1177/ 1040638711425936 .

Britten, A. 2003. Surviving a Mycoplasma outbreak: Step by step. Pages. 1-4 in the Proceedings of the National Mastitis Council Regional Meeting. National Mastitis Council.

Britten, A. M., E. D. Tretter, and J. E. Britten. 2020. Why species matter? Dramatic revelations in Mycoplasma mastitis management with molecular diagnostics. Pages 193-194 in Proceedings of the National Mastitis Council Meeting. National Mastitis Council.

Bushnell, R. B. 1984. Mycoplasma mastitis. Vet. Clin. North Am. Large Anim. Pract. 6:301-312.

Caswell, J. L., and M. Archambault. 2007. Mycoplasma bovis pneumonia in cattle. Anim. Health Res. Rev. 8:161-186. https://doi.org/ $10.1017 /$ S1466252307001351.

Catania, S., A. Tavella, F. Gobbo, and R. A. Nicholas. 2014. Isolation of Mycoplasma bovigenitalium from infertile dairy cattle. Vet. Rec. Case Rep. 2:e00055. https://doi.org/10.1136/vetreccr-2014 -000055 .
DelGiudice, R. A., T. R. Carski, M. F. Barile, R. M. Lemcke, and J. G. Tully. 1971. Proposal for classifying human strain navel and related simian mycoplasmas as Mycoplasma primatum sp. nov. J. Bacteriol. 108:439-445. https://doi.org/10.1128/JB.108.1.439-445 .1971.

Djordjevic, S. R., W. A. Forbes, J. Forbes-Faulkner, P. Kuhnert, S. Hum, M. A. Hornitzky, E. M. Vilei, and J. Frey. 2001. Genetic diversity among Mycoplasma species bovine group 7: Clonal isolates from an outbreak of polyarthritis, mastitis, and abortion in dairy cattle. Electrophoresis 22:3551-3561. https://doi.org/10.1002/ 1522-2683(200109)22:16<3551::AID-ELPS3551>3.0.CO;2-\#.

Fox, L. K. 2012. Mycoplasma mastitis: Causes, transmission, and control. Vet. Clin. North Am. Food Anim. Pract. 28:225-237. https:/ /doi.org/10.1016/j.cvfa.2012.03.007.

Fox, L. K., D. D. Hancock, A. Mickelson, and A. Britten. 2003. Bulk tank milk analysis: Factors associated with appearance of Mycoplasma sp. in milk. J. Vet. Med. B Infect. Dis. Vet. Public Health 50:235-240. https://doi.org/10.1046/j.1439-0450.2003.00668.x.

Fox, L. K., J. H. Kirk, and A. Britten. 2005. Mycoplasma mastitis: A review of transmission and control. J. Vet. Med. B Infect. Dis. Vet. Public Health 52:153-160. https://doi.org/10.1111/j.1439-0450 2005.00845.x.

Gioia, G., B. Werner, D. V. Nydam, and P. Moroni. 2016. Validation of a mycoplasma molecular diagnostic test and distribution of mycoplasma species in bovine milk among New York State dairy farms. J. Dairy Sci. 99:4668-4677. https://doi.org/10.3168/jds 2015-10724.

González, R. N., and D. J. Wilson. 2003. Mycoplasmal mastitis in dairy herds. Vet. Clin. North Am. Food Anim. Pract. 19:199-221. https://doi.org/10.1016/S0749-0720(02)00076-2.

Hata, E., K. Nagai, and K. Murakami. 2017. Complete genome sequence of Mycoplasma bovigenitalium strain HAZ 596 from a bovine vagina in Japan. Genome Announc. 5:e01554-16. https://doi .org/10.1128/genomeA.01554-16.

Hazelton, M. S., J. M. Morton, A. M. Parker, P. A. Sheehy, K. L. Bosward, J. Malmo, and J. K. House. 2020. Whole dairy herd sampling to detect subclinical intramammary Mycoplasma bovis infection after clinical mastitis outbreaks. Vet. Microbiol. 244:108662. https://doi.org/10.1016/j.vetmic.2020.108662.

Hazelton, M. S., P. A. Sheehy, K. L. Bosward, A. M. Parker, J. M. Morton, C. J. Dwyer, P. G. Niven, and J. K. House. 2018. Short communication: Shedding of Mycoplasma bovis and antibody responses in cows recently diagnosed with clinical infection. J. Dairy Sci. 101:584-589. https://doi.org/10.3168/jds.2017-13512.

Higuchi, H., H. Iwano, K. Kawai, T. Ohta, T. Obayashi, K. Hirose, N. Ito, H. Yokota, Y. Tamura, and H. A. Nagahata. 2011. Simplified PCR assay for fast and easy mycoplasma mastitis screening in dairy cattle. J. Vet. Sci. 12:191-193. https://doi.org/10.4142/jvs .2011.12.2.191.

Jackson,, G.,. and E. Boughton. 1991. A mild outbreak of bovine mastitis associated with Mycoplasma bovigenitalium. Vet. Rec 129:444-446. https://doi.org/10.1136/vr.129.20.444.

Jasper, D. E. 1979. Bovine mycoplasmal mastitis. J. Am. Vet. Med. Assoc. 175:1072-1074.

Jasper, D. E. 1981. Bovine mycoplasmal mastitis. Pages 121-157 in Advances in Veterinary Sciences and Comparative Medicine. C. E. Cornelius and B. F. Simpson, ed. Academic Press.

Jasper, D. E. 1982. The role of Mycoplasma in bovine mastitis. J. Am. Vet. Med. Assoc. 181:158-162.

Justice-Allen, A., J. Trujillo, G. Goodell, and D. Wilson. 2011. Detection of multiple Mycoplasma species in bulk tank milk samples using real-time PCR and conventional culture and comparison of test sensitivities. J. Dairy Sci. 94:3411-3419. https://doi.org/10 $.3168 /$ jds.2010-3940.

Kokotovic, B., N. F. Friis, and P. Ahrens. 2007. Mycoplasma alkalescens demonstrated in bronchoalveolar lavage of cattle in Denmark. Acta Vet. Scand. 49:2. https://doi.org/10.1186/1751-0147-49-2.

Mackie, D. P., H. J. Ball, and E. F. Logan. 1982. Isolation of Mycoplasma californicum from an outbreak of bovine mastitis and the experimental reproduction of the disease. Vet. Rec. 110:578-580. https://doi.org/10.1136/vr.110.25.578. 
Mackie, D. P., H. J. Ball, and E. F. Logan. 1986. Mycoplasma californicum mastitis in the dry dairy cow. Vet. Rec. 119:350-351. https: //doi.org/10.1136/vr.119.14.350.

Mackie, D. P., D. Finlay, N. Brice, and H. J. Ball. 2000. Mixed mycoplasma mastitis outbreak in a dairy herd. Vet. Rec. 147:335-336. https://doi.org/10.1136/vr.147.12.335.

Nagatomo, H., Y. Takegahara, T. Sonoda, A. Yamaguchi, R. Uemura, S. Hagiwara, and M. Sueyoshi. 2001. Comparative studies of the persistence of animal mycoplasmas under different environmental conditions. Vet. Microbiol. 82:223-232. https://doi.org/10.1016/ s0378-1135(01)00385-6.

National Mastitis Council (NMC). 2017. Laboratory Handbook on Bovine Mastitis. National Mastitis Council.

Nicholas, R. A. 2011. Bovine mycoplasmosis: Silent and deadly. Vet. Rec. 168:459-462. https://doi.org/10.1136/vr.d2468.

Nicholas, R. A., L. K. Fox, and I. Lysnyansky. 2016. Mycoplasma mastitis in cattle: To cull or not to cull. Vet. J. 216:142-147. https:// doi.org/10.1016/j.tvjl.2016.08.001.

Parker, A. M., P. A. Sheehy, M. S. Hazelton, K. L. Bosward, and J. K. House. 2018. A review of mycoplasma diagnostics in cattle. J. Vet. Intern. Med. 32:1241-1252. https://doi.org/10.1111/jvim.15135.

Parkinson, T. J. 2019. Specific infectious diseases causing infertility and subfertility in cattle. Pages 434-466 in Veterinary Reproduction and Obstetrics. 10th ed. W.B. Saunders.

Pfützner, H., and K. Sachse. 1996. Mycoplasma bovis as an agent of mastitis, pneumonia, arthritis and genital disorders. Rev. Sci. Tech. 15:1477-1494. https://doi.org/10.20506/rst.15.4.987.

Pinho, L., G. Thompson, M. Machado, and J. Carvalheira. 2013. Management practices associated with the bulk tank milk prevalence of Mycoplasma spp. in dairy herds in Northwestern Portugal. Prev. Vet. Med. 108:21-27. https://doi.org/10.1016/j.prevetmed.2012.07 .001 .

Punyapornwithaya, V., L. K. Fox, D. D. Hancock, J. M. Gay, and J. R. Alldredge. 2010. Association between an outbreak strain causing
Mycoplasma bovis mastitis and its asymptomatic carriage in the herd: A case study from Idaho, USA. Prev. Vet. Med. 93:66-70. https://doi.org/10.1016/j.prevetmed.2009.08.008.

Quinn, P. J., B. K. Markey, F. C. Leonard, S. Fanning, and D. Maguire. 2013. Veterinary Microbiology and Microbial Disease. 2nd ed. Wiley.

Rosenbusch, R. F. 2003. Mycoplasma: What we know about mastitis and systemic disease. Pages 8-13 in Proc. Minn. Dairy Health Conf.

Stipkovits, L., M. Somogyi, B. Asvanyi, A. Toth, and S. Szathmary. 2013. Short communication: Role of Mycoplasma arginini in mastitis caused by Streptococcus dysgalactiae. J. Dairy Sci. 96:16611667. https://doi.org/10.3168/jds.2012-5669.

Thomas, A., H. Ball, I. Dizier, A. Trolin, C. Bell, J. Mainil, and A. Linden. 2002. Isolation of mycoplasma species from the lower respiratory tract of healthy cattle and cattle with respiratory disease in Belgium. Vet. Rec. 151:472-476. https://doi.org/10.1136/vr.151 .16 .472 .

\section{ORCIDS}

G. Gioia ๑ https://orcid.org/0000-0003-1767-9497

M. F. Addis ๑ https://orcid.org/0000-0001-6934-7748

D. V. Nydam @ https://orcid.org/0000-0001-7717-4859

A. S. Sipka @ https://orcid.org/0000-0002-8646-824X

P. D. Virkler @ https://orcid.org/0000-0002-9177-4663

R. D. Watters @ https://orcid.org/0000-0002-7714-5887

M. Wieland (๑) https://orcid.org/0000-0003-0513-1782

M. J. Zurakowski ๑ https://orcid.org/0000-0001-5320-6342

P. Moroni $\odot$ https://orcid.org/0000-0002-0974-3084 